\title{
EFEKTIFITAS MODEL KARAKTERISTIK ARUS LALU LINTAS PADA RUAS JALAN SIMPANG 4 BIREUN (PERBANDINGAN DENGAN METODE GREENSHIELD, GREENBERG, UNDERWOOD)
}

\author{
Adzuha Desmi ${ }^{1)}$, Lis Ayu Widari ${ }^{2)}$, Riza Yanti ${ }^{3)}$ \\ Jurusan Teknik Sipil, Fakultas Teknik, Universitas Malikussaleh \\ Email:adz.desmi@gmail.com ${ }^{1)}$, lisayuwidari@gmail.com $^{21}$ \\ DOI: http://dx.doi.org/10.29103/tj.v9i1.178
}

\begin{abstract}
Abstrak
Pada penelitian ini, karakteristik arus lalu lintas dianalisa dengan menggunakan beberapa metode, bertujuan untuk menganalisa perbandingan model karakteristik lalu lintas pada ruas jalan Simpang 4 Bireun dengan menggunakan metode MKJI 1997, dan melakukan perbandingan dengan model Greenshield, Greenberg dan Underwood. Efektifitas dan efisiensi dari penyajian data yang ditampilkan oleh masing - masing metode tersebut. Hasil penelitian memperlihatkan bahwa hasil model matematis untuk Model Greenshield adalah (S) sebesar 40,6231 km/jam, sedangkan Greenberg (S) sebesar 37,92 km/jam dan Underwood (S) sebesar 40,668 km/jam. Untuk hubungan kecepatan kepadatan maka Greenberg memiliki pendekatan yang lebih baik, sedangkan untuk hubungan volume kepadatan, keduanya menunjukkan hasil yang hampir sama, dan untuk hubungan volume kecepatan maka pendekatan Greenshield dan Underwood masih lebih baik.
\end{abstract}

Kata kunci: greenshield, greenberg, underwood, speed vehicles, traffic flow, Density of Traffic

\begin{abstract}
In this study, characteristics of the traffic flow are studied and analyzed using several methods. This study aims to analyze the comparison of traffic characteristic model on Simpang 4 Bireun road using MKJI 1997 method, and to compare with Greenshield, Greenberg and Underwood models. The effectiveness and efficiency of the data presentation presented by each method. The results of the mathematical model for Greenshield Model are (S) as $40.6231 \mathrm{~km} / \mathrm{hr}$, Greenberg (S) as $37.92 \mathrm{~km} / \mathrm{hr}$ and Underwood (S) as $40.668 \mathrm{~km} / \mathrm{hr}$. For the relationship of density velocity, Greenberg has a better approach, whereas for the density volume relationship, they show almost the same result, and for the volume velocity relationship, the Greenshield and Underwood approaches are still better.
\end{abstract}

Keywords: greenshield, greenberg, underwood, speed vehicles, traffic flow, density of traffic

\section{Latar Belakang}

Pembangunan ruas jalan sebagai salah satu bentuk komitmen pemerintah dalam pembangunan infrastruktur secara menyeluruh dimaksudkan sebagai penyedia sarana transportasi yang memudahkan masyarakat setempat untuk berinteraksi dengan lingkungan sekitarnya, baik dalam bidang sosial, ekonomi maupun budaya. Sebagai salah satu adalah sarana transportasi darat. Jalan raya dimaksudkan untuk dipergunakan sebagai akumulasi berbagai kendaraan

Komparasi Metode Greenshield, Greenberg Dan Underwood Terhadap Efektifitas Model Karakteristik Arus Lalu Lintas Pada Ruas Jalan Simpang 4 Bireuen - Adzuha 
bermotor maupun kenderaan tak bermotor. Dan dalam hal ini jumlah atau volume dari kendaraan yang melintasi jalan tersebut tergantung kepada berbagai parameter yang ada antara lain kepadatan penduduk, jumlah kendaraan serta kondisi jalan.

Jalan raya simpang 4 Bireuen adalah salah satu jalan arteri di kota Bireun yang memiliki volume kendaraan yang cukup tinggi, terutama pada saat musim sekolah, di mana ruas jalan raya ini yang memiliki ribuan mahasiswa serta adanya deretan toko disepanjang jalan tersebut. Kondisi jalan yang dinamis tersebut menimbulkan kerawanan berupa kemacetan kendaraan yang melalui ruas jalan tersebut. Jumlah pergerakan di Bireuen dapat dikaitkan dengan kepadatan arus lalu lintas pada ruas jalan tersebut. Kepadatan dapat diyakini berkorelasi dengan kecepatan kendaraan serta volume kendaraan yang terjadi perkilometer ruas jalan.

Dengan melihat kepada latar belakang yang ada maka dapat dikemukakan beberapa permasalahan yang ada yaitu ; bagaimanakah bentuk model matematis dari karakteristik ruas jalan simpang 4 Bireuen tersebut, berapakah kecepatan minimum yang harus ditempuh seorang pengguna jalan yang melintasi jalan Raya simpang 4 Bireun, dan model manakah yang paling optimal yang dapat menggambarkan kondisi riil dari karakteristik ruas jalan tersebut.

Tujuan dari penelitian ini antara lain ingin mengetahui model matematis antara kecepatan - kepadatan, volume-kecepatan dan volume-kepadatan diarus jalan Raya simpang 4 Bireuen, mengetahui nilai kecepatan minimum dan kecepatan optimal dari kendaraan yang melaju pada ruas jalan tersebut, dan Mengetahui Model Greenshield, Model Greenberg dan Underwood.

Penelitian ini dimaksudkan untuk mencari model korelasi antara volume kendaraan, arus dan kecepatan kendaraan pada ruas jalan. Ruas jalan yang diteliti pada area simpang 4 Bireuen, pemilihan ini didasari oleh observasi awal di mana pada ruas jalan ini sering terjadi kemacetan, volume kendaraan yang meningkat pada jam-jam tertentu. Serta belum ada suatu studi yang bermodelkan korelasi arus dan kepadatan pada ruas jalan ini.

\section{Metode Penelitian}

\subsection{Pengumpulan data}

Penelitian ini meliputi persiapan, pengambilan data lapangan maka dilakukan persiapan terlebih dahulu berupa pembuatan batas awal dan akhir, diusahakan tanda pembatas yang baik untuk $100 \mathrm{~m}$ dapat dilihat oleh pengamat di mana tanda tersebut dibuat dengan menggunakan cat warna merah yang dioleskan pada tempat-tempat yang terlihat oleh pengamat. Lokasi penelitian di persimpangan jalan Medan-Banda Aceh, jalan Banda Aceh Medan, jalan BireuenTakengon, jalan Kuala Raja Bireuen seperti diperlihatkan pada Gambar 1

Pengambilan data primer berupa volume lalu lintas, kecepatan kendaraan ringan, dilakukan secara bersamaan di lokasi penelitian selama 4 hari dari jam 07.00 Wib sampai dengan 18.00 Wib, sedangkan data geometrik jalan berupa lebar jalur lalu lintas (m), lebar jalan masuk ke jalan utama m), kereb, jarak kereb-penghalang $(\mathrm{m})$ dilakukan pada malam hari agar tidak menggangu aktifitas lalu lintas pada saat penelitian.

Metode pengumpulan data berupa data primer dan sekunder, data primer diperoleh dari survey lapangan (Sudjana, 1992) berupa volume lalu lintas, kecepatan lalu lintas, waktu tempuh kendaraan dan pengukuran geometrik jalan,

Komparasi Metode Greenshield, Greenberg Dan Underwood Terhadap Efektifitas Model Karakteristik Arus Lalu Lintas Pada Ruas Jalan Simpang 4 Bireuen - Adzuha 
dari data tersebut kemudian akan diolah untuk mendapatkan data kepadatan lalu lintas. Data sekunder sebagai pelengkap data penunjang di lapangan meliputi peta jaringan jalan diperoleh dari dinas Pekerjaan Umum, Dinas Perhubungan, dinas Statistik dan sketsa lokasi pengamatan pada jalan yang ditinjau.

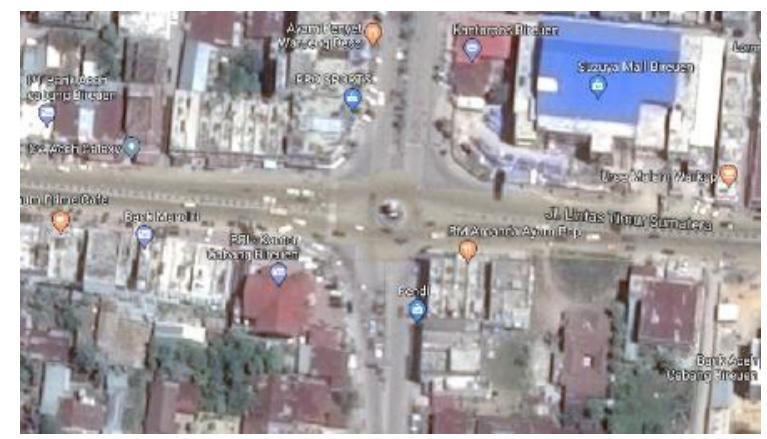

Gambar 1 Lokasi penelitian

Volume lalu lintas adalah jumlah kendaraan yang melewati suatu titik pada segmen jalan dalam interval waktu tertentu yang dinyatakan dalam kendaraan persatuan waktu tertentu volume lalu lintas rata- rata adalah kendaraan rata- rata di hitung menurut satu satuan waktu tertentu, bisa harian yang di katakan sebagai volume lalu lintas harian rata-rata/LHR atau dalam bahasa Inggris di sebut sebagai Average Daily Traffic Volume (ADT). Menurut Morlok, (1988), volume lalu lintas dapat di hitung dengan menggunakan rumus berikut:

$$
q=\frac{n}{t}
$$

di mana:

$$
\begin{aligned}
\mathrm{q}= & \text { Volume lalu lintas yang melalui suatu titik, } \\
\mathrm{n}= & \text { Jumlah kendaraan yang melalui titik itu dalam interval waktu } \\
& \text { pengamatan, } \\
\mathrm{t}= & \text { Interval waktu pengamatan. }
\end{aligned}
$$

Parameter arus lalu lintas dibagi menjadi 2 kategori; (a). Parameter makroskopik mencirikan arus lalu lintas secara keseluruhan, (b). Parameter mikroskopik mencirikan perilaku individual kendaraan yang di dalam arus lalu lintas satu sama lain saling memberi kesempatan. Secara makroskopik, arus lalu lintas digambarkan/dicirikan oleh 3 parameter utama (a). Volume atau tingkat arus (volume or rate of flow). (b). Kecepatan (speed), (c). Kerapatan (density). Selain itu digunakan pula parameter headway (h), spacing (s), dan occupancy (R). Terkait pada headway dan spacing, ada parameter clearance (c) dan gap (g).

Pengamatan kecepatan setempat dilakukan atas sejumlah kendaraan. Hal tersebut didasarkan atas ketidaksamaan kecepatan masing- masing kendaraan oleh pengaruh berbagai keadaan, baik kendaraan, pengemudi, kepadatan sesaat dan sebagainya. Karena itu, untuk memperoleh kecepatan setempat, maka digunakan prosedur statistik yang disederhanakan. Kecepatan menggambarkan tingkat pergerakan kendaraan yang dinyatakan dalam jarak tempuh persatuan waktu atau nilai perubahan jarak terhadap waktu. Satuannya adalah kilometer/jam, meter/detik. Menurut Tamin O. Z., (2003) kecepatan didefinisikan sebagai jarak 
yang dapat ditempuh suatu kendaraan persatuan waktu. Satuan yang biasa digunakan adalah meter/detik atau kilometer/jam. Adapun rumus untuk menghitung kecepatan (Morlok, E.K. 1988):

$$
V=\frac{d}{t}
$$

di mana:

$\mathrm{V}=\operatorname{Kecepatan}(\mathrm{km} / \mathrm{jam}, \mathrm{m} / \mathrm{det})$,

$\mathrm{d}=$ Jarak tempuh $(\mathrm{km}, \mathrm{m})$,

$\mathrm{t}=$ Waktu tempuh (jam, detik).

Terdapat 3 klasifikasi kecepatan pada lalu lintas (Ahmad Munawar, 2005) a). Kecepatan titik/sesaat (spot speed), keadaan dimana kendaraan mengalami kecepatan yang stabil pada suatu titik, b). Kecepatan perjalanan (journey speed), kecepatan rata-rata dimana nilainya dapat ditentukan dari jarak perjalanan dibagi dengan total waktu perjalanan, c). Kecepatan bergerak (running speed), kecepatan rata-rata kendaraan untuk melintasi suatu jarak tertentu dalam kondisi kendaraan tetap berjalan, yaitu kondisi setelah dikurangi oleh waktu hambatan terjadi (misalnya hambatan pada persimpangan). Kecepatan bergerak ini dapat ditentukan dari jarak perjalanan dibagi total waktu perjalanan yang telah dikurangi dengan waktu berhenti karena adanya hambatan yang disebabkan gangguan yang terjadi pada lalu lintas.

Untuk mengetahui nilai kepadatan lalu lintas diperoleh dari pengolahan data volume dan kecepatan lalu lintas, yaitu dari hasil perbandingan antara nilai volume dengan kecepatan lalu lintas pada waktu pengamatan yang sama. Nilai kepadatan lalu lintas dinyatakan dalam satuan smp/km.

\subsection{Hubungan kecepatan, kepadatan dan volume lalu lintas}

Hubungan antara kecepatan, volume dan kerapatan dapat digambarkan secara grafis sebagaimana diperlihatkan pada Gambar 2 (Khisty C.J., Kent Lall., 2003). Dari kurva terlihat bahwa hubungan mendasar antara volume dan kecepatannya adalah dengan bertambahnya volume lalu lintas, maka kecepatan rata-rata ruangannya akan berkurang sampai volume maksimum tercapai. Hubungan antara kecepatan dan kerapatan menunjukkan bahwa kecepatan akan menurun apabila kerapatan bertambah. Hubungan antara volume dan kerapatan memperlihatkan bahwa kerapatan akan bertambah apabila volumenya juga bertambah.

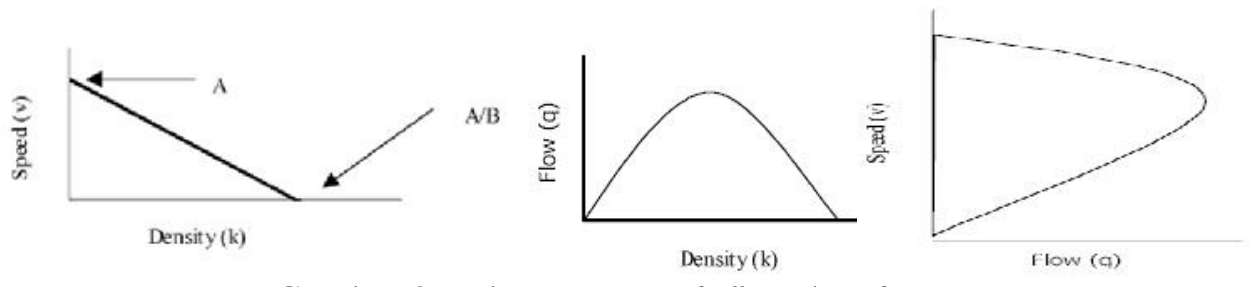

Gambar 2 Hubungan speed, flow dan density

\subsection{Model Greenshield}

Greenshield merumuskan bahwa hubungan matematis antara kecepatankepadatan diasumsikan linear (Ofyar Tamin,2000) seperti yang dinyatakan dalam persamaan (2). Model ini adalah model paling awal yang tercatat dalam usaha

Komparasi Metode Greenshield, Greenberg Dan Underwood Terhadap Efektifitas Model Karakteristik Arus Lalu Lintas Pada Ruas Jalan Simpang 4 Bireuen - Adzuha 
mengamati perilaku arus lalu lintas. Greenshields (1934) mendapatkan hasil bahwa hubungan antara kecepatan dan kepadatan berbentuk kurva linier (McShane dan Roes,1990).

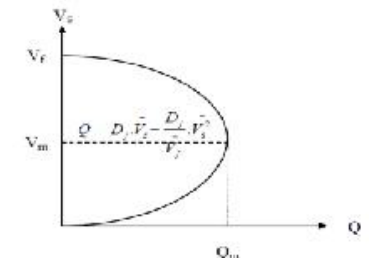

a. Hubungan kecepatan dan volume kepadatan

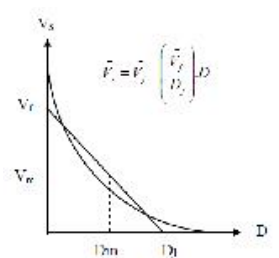

b. Hubungan kecepatan dan

Gambar 3 Hubungan arus dan kepadatan

Kecepatan pada saat Volume maksimum didapat dengan menggunakan persamaan:

$$
V_{s}=V_{m}=\frac{V_{f}}{2}
$$

\subsection{Model Greenberg}

Hubungan Volume dan Kecepatan pada model Greenberg ini menggunakan persamaan sebagai berikut:

$$
Q=V_{s} \cdot D_{j} \cdot \exp \frac{-V_{s}}{V_{m}}
$$

Hubungan Volume Dan Kepadatan ini berlaku persamaan sebagai berikut:

$$
\begin{aligned}
& Q=V_{m} \cdot D \cdot L_{n} \frac{D_{j}}{D} \\
& Q m a k s=\frac{D_{j} \cdot V_{m}}{e}=V_{m} \cdot D_{m}
\end{aligned}
$$

Kecepatan pada saat volume maksimum didapat:

$$
V_{\mathrm{s}}=\mathrm{V}_{\mathrm{m}}
$$

\subsection{Model Underwood}

Untuk mendapatkan hubungan antara variabel volume, kecepatan dan kepadatan menurut model eksponensial Underwood digunakan hubungan volume dan kecepatan model Underwood ini berlaku persamaan sebagai berikut:

$$
Q=V_{f} \cdot D_{m} \cdot \operatorname{Ln}\left(\frac{V_{f}}{V_{s}}\right)
$$

Hubungan volume dan kepadatan berlaku persamaan berikut:

$$
Q=D \cdot V_{f} \cdot \exp \left(\frac{-D}{D_{m}}\right)
$$

Volume maksimum (Qmaks) adalah:

$$
\text { Qmaks }=\frac{D_{m} \cdot V_{f}}{\exp }
$$

Komparasi Metode Greenshield, Greenberg Dan Underwood Terhadap Efektifitas Model Karakteristik Arus Lalu Lintas Pada Ruas Jalan Simpang 4 Bireuen - Adzuha Desmi, Lis Ayu Widari, Riza Yanti 
Kecepatan pada saat volume maksimum (Qmaks) didapat dengan menggunakan persamaan:

$$
V_{m}=\frac{V_{f}}{\exp }
$$

\subsection{Analisis Hubungan}

Menurut Ririn Gamran et all (1977), hubungan antara ketiga variabel kecepatan, kerapatan dan volume disusun berdasarkan data arus lalu lintas dan kecepatan kendaraan yang diambil tiap periode 5 menitan yang disusun dalam suatu daftar secara berpasangan selanjutnya nilai kerapatan dapat dicari dengan persamaan dasar $\mathrm{V}=\mathrm{D}$. U $\mathrm{U}_{\mathrm{S}}$. Hubungan antara kecepatan $\left(\mathrm{U}_{\mathrm{S}}\right)$, kerapatan (D) dan arus (V), dianalisis dengan menggunakan tiga metode yakni metode Greenshield, Greenberg dan Underwood. Penyelesaian statistik didekati dengan mencari hubungan antara kecepatan dan kerapatan melalui metode regresi. Hubungan antara kecepatan dan kerapatan masing-masing dengan metode Greenshield, Greenberg dan Underwood adalah sebagai berikut:

$$
\begin{aligned}
& \text { a. Greenshield: } U_{s}=U_{f}-\left(\frac{U_{f}}{D_{j}}\right) \cdot D \\
& \text { b. Greenberg }: U_{s}=U_{m} \cdot \operatorname{Ln}\left(\frac{D_{j}}{D}\right) \\
& \text { c. Underwood }: U_{s}=U_{f} \cdot e \frac{-D}{D_{m}}
\end{aligned}
$$

\subsection{Road Map Penelitian dan Perbandingan Antara Penelitian ini dengan Penelitian Sebelumnya.}

Penelusuran terhadap penelitian sebelumnya dilakukan sebagai bahan komparasi terhadap penelitian ini sebagaimana diperlihatkan pada Tabel 1

Tabel 1 Road map penelitian dan penelitian sebelumnya.

\begin{tabular}{ccccccccc}
\hline Jurnal & $\begin{array}{c}\text { Roux } \\
\text { J., 2002 }\end{array}$ & $\begin{array}{c}\text { Tamin } \\
\text { Z .O., } \\
1992\end{array}$ & $\begin{array}{c}\text { Mashuri, } \\
2006\end{array}$ & $\begin{array}{c}\text { Juliant } \\
\text { o N. E., } \\
2010\end{array}$ & $\begin{array}{c}\text { Gregory } \\
\text { K. L., } \\
2012\end{array}$ & $\begin{array}{c}\text { Jun J., } \\
2012\end{array}$ & $\begin{array}{c}\text { Yuniar } \\
\text { D., 2013 }\end{array}$ & $\begin{array}{c}\text { Iskandar } \\
\text { H., 2012 }\end{array}$ \\
\hline $\begin{array}{c}\text { Jenis } \\
\text { Jalan }\end{array}$ & Tol & Arteri & Arteri & Arteri & Arteri & Tol & Arteri & Tol \\
\hline Lokasi & $\begin{array}{c}\text { Cape } \\
\text { Town }\end{array}$ & Jakarta & Palu & $\begin{array}{c}\text { Semara } \\
\text { ng }\end{array}$ & Iloilo & $\begin{array}{c}\text { Virginia } \\
\text { Utara }\end{array}$ & $\begin{array}{c}\text { Kalimant } \\
\text { an }\end{array}$ & Bandung \\
\hline Metode & $\begin{array}{c}\text { Greenb } \\
\text { erg }\end{array}$ & $\begin{array}{c}\text { Under } \\
\text { wood }\end{array}$ & $\begin{array}{c}\text { Greenshi } \\
\text { eld }\end{array}$ & $\begin{array}{c}\text { Under } \\
\text { wood }\end{array}$ & $\begin{array}{c}\text { JICA } \\
\text { STRADA }\end{array}$ & - & $\begin{array}{c}\text { Greenshi } \\
\text { eld }\end{array}$ & $\begin{array}{c}\text { MKJI ., } \\
1997\end{array}$ \\
\hline
\end{tabular}

Berdasarkan tabel diatas yang dapat diambil untuk dijadikan refrensi pada penelitian ini adalah sebagai berikut :

a. Mashuri, (2006) melakukan penelitian tentang kepadatan arus lalu lintas yang ada di ruas jalan arteri di Palu. Penelitian ini membahas tentang hubungan parameter kecepatan, volume dan kepadatan menggunakan metode Greenshield. 
b. Tamin Z. O., (1992) melakukan penelitian tentang hubungan antara kecepatan dan volume lalu lintas di Jalan H.R. Rasuna Said, Jakarta. Penelitian ini membahas tentang hubungan parameter kecepatan, volume dan kepadatan menggunakan metode Underwood.

c. Julianto N. O., (2010) melakukan penelitian tentang tentang hubungan antara kecepatan dan volume lalu lintas di ruas Jalan Semarang Penelitian ini membahas tentang hubungan parameter kecepatan, volume dan kepadatan menggunakan metode Underwood.

Perbedaan ketiga penelitian di atas dengan penelitian ini adalah lokasi ruas jalan penelitian yang akan dilakukan bukan jalan arteri melainkan ruas jalan yang dipilih merupakan jalan tol yang mana tidak memiliki hambatan samping yang besar serta perbedaan kapasitas kecepatan yang lebih tinggi. Kemudian data kecepatan dan volume akan digunakan untuk menghitung density kendaraan saat masa peak hour menggunakan dasar perhitungan MKJI, 1997. Dari data-data yang sudah diolah akan dibuat suatu grafik hubungan antara kecepatan dan density untuk kemudian diperoleh besaran angka kecepatan optimum saat kepadatan jalan raya cenderung rapat.

\subsection{Metode Analisa Data}

Untuk mengetahui hubungan matematis antara parameter tersebut, dengan beberapa set data bisa didapat dari hasil survey di lokasi pengamatan menggunakan persamaan diperoleh nilai A dan B. Seluruh analisis perhitungan perbandingan dengan model Greenshield, Greenberg dan Underwood. Dari hasil perhitungan tersebut dapat di tentukan hubungan antara kecepatan dan kepadatan lalu lintas.

\section{Hasil dan Pembahasan}

\subsection{Hasil}

\subsubsection{Volume Lalu Lintas}

Berdasarkan Hasil Pengolahan data volume lalu lintas diperoleh total volume pada setiap hari pengamatan smp/jam, hasil selengkapnya di tampilkan dalam Tabel 2.

Tabel 2 Rekapitulasi volume lalu lintas rata-rata

\begin{tabular}{cccc}
\hline No & hari/Tgl & $\begin{array}{c}\text { Volume Rata-rata } \\
\text { (smp/15 Menit) }\end{array}$ & $\begin{array}{c}\text { Volume Rata-rata } \\
\text { (smp/jam) }\end{array}$ \\
\hline 1 & Senin & 1065,53 & 4664,37 \\
\hline 2 & Selasa & 918,32 & 3699,24 \\
\hline 3 & Rabu & 699,1 & 2807,08 \\
\hline 4 & Kamis & 1481,99 & 6117,62 \\
\hline
\end{tabular}

Berdasarkan Hasil penelitian arus lalu lintas yang paling besar adalah arah jalan Banda Aceh-Medan karena jalan ini merupakan jalan utama menuju pusat Kota Bireun apalagi saat jam puncak. Berdasarkan Grafik fluktuasi, volume lalu

Komparasi Metode Greenshield, Greenberg Dan Underwood Terhadap Efektifitas Model Karakteristik Arus Lalu Lintas Pada Ruas Jalan Simpang 4 Bireuen - Adzuha Desmi, Lis Ayu Widari, Riza Yanti 
lintas dari arah jalan Banda Aceh-Medan yang melewati persimpangan ini cukup padat hingga mencapai angka 29237,60 (smp/jam), karena pada pagi hari merupakan pucak pertama dari rutinitas setiap orang dalam mengawali harinya.

Berdasarkan pengolahan data harian, volume jam puncak terdapat pada hari selasa yaitu dengan jumlah 2292,20 (smp/ jam) pagi pukul 12.00-13.00. dan siang dengan jumlah 2128,10 (smp/jam) pukul 17.00-18.00. Fluktasi Volume Lalu lintas yang dihasilkan dari survey tersebut digunakan untuk mengetahui jam-jam puncak yaitu jam puncak pagi (07.00-08.00), jam puncak siang(12.00-13.00), dan jam puncak sore (17.00-18.30).

\subsubsection{Kecepatan Lalu Lintas}

Dari hasil pengolahan data, maka diperoleh kecepatan setempat rata-rata pada arah Bireun Medan-Banda Aceh yaitu senin 29,00 km/jam, selasa jalan JuliTakengon 28,91 km/jam, kamis jalan Banda Aceh-Medan 29,93 km/jam, minggu jalan Kuala Raja 30,57 km/jam.

\subsubsection{Kepadatan Lalu Lintas}

Untuk mengetahui nilai kepadatan lalu lintas diperoleh dari pengolahan data volume dan kecepatan lalu lintas, yaitu dari hasil perbandingan antara nilai volume dengan kecepatan lalu lintas pada waktu pengamatan yang sama. Nilai kepadatan lalu lintas dinyatakan dalam satuan smp/km.

\subsection{Pembahasan}

Dari hasil grafik hubungan antara volume dengan kepadatan lalu lintas dapat diperoleh kondisi kecepatan maksimum (D) 3297,83 smp/km. Kondisi tersebut merupakan kondisi yang lebih rill mendekati model Greenberg, karena hanya satu kondisi kepadatan yang terjadi dan dilihat dari persamaan-persamaan menunjukkan bahwa kondisi kecepatan maksimum dipengaruhi oleh kepadatan lalu lintas.

Dari grafik hubungan kecepatan dan kepadatan dapat dijelaskan bahwa apabila kepadatan meningkat dari nol maka kecepatan lalu lintas terus meningkat, sehingga melebihi dari kepadatan pada kondisi optimum, maka akan dicapai suatu kondisi dimana peningkatan kepadatan lalu lintas tidak akan meningkat arus lalu lintas, malah sebaliknya akan menurunkan arus lalu lintas.

Hubungan matematis antara kecepatan dengan kepadatan lalu lintas menggunakan model Greenshield dan underwood menunjukkan kecepatan kepadatan lalu lintas lemah, di mana dapat dijelaskan bahwa apabila kepadatan lalu lintas terus meningkat sehingga melebihi kepadatan optimum maka mengakibatkan menurunnya kecepatan lalu lintas (Hendra Wibisana, 2007).

Hasil yang diperoleh menunjukkan bahwa hubungan yang terjadi antara kecepatan dengan kepadatan lalu lintas adalah melihat ke bawah. Hasil ini sesuai dengan apa yang diasumsikan oleh metode Greenberg sebelumnya, yaitu hubungan matematis antara kecepatan dengan kepadatan lalu lintas adalah menoton ke bawah, hanya saja terdapat perilakunya yang sedikit berbeda.

Pada penelitian ini di gunakan analisa perbandingan model karakteristik lalu lintas yang ada yaitu Greenshield, Greenberg dan Underwood, efektifitas dan efisiensi dari penyajian data yang ditampilkan oleh masing- masing metode tersebut dan dari ketiga metode tersebut dibandingkan mana yang lebih optimal

Komparasi Metode Greenshield, Greenberg Dan Underwood Terhadap Efektifitas Model Karakteristik Arus Lalu Lintas Pada Ruas Jalan Simpang 4 Bireuen - Adzuha 
dalam memberikan solusi dari pergerakan kendaraan dari hubungan antara kepadatan, kecepatan, dan nilai yang lebih optimal terdapat pada model Greenberg.

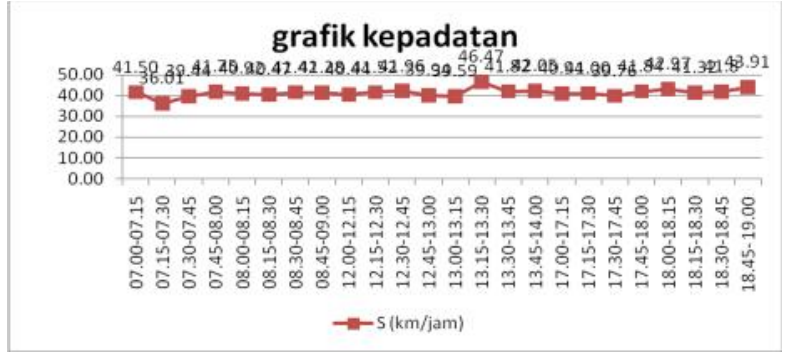

Gambar 4 perhitungan greenshield

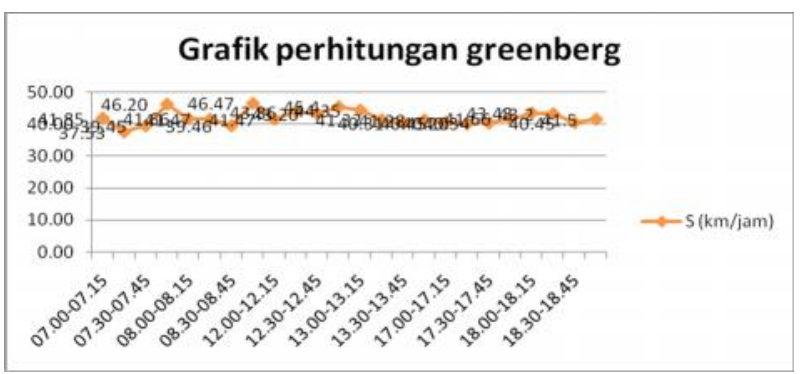

Gambar 5 Perhitungan Greenberg

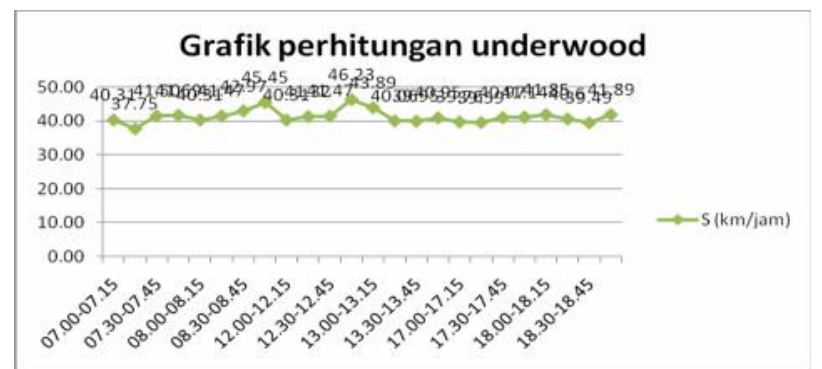

Gambar 6 Perhitungan Underwood

Hasil grafik model Greenshield pada penelitian ini (Gambar 4) menunjukkan bahwa kepadatan optimum rendah. Sedangkan hasil Gambar 6 menunjukkan bahwa kepadatan lebih rendah dari Gambar 4. Untuk hubungan kecepatan kepadatan maka Gambar 5 memiliki nilai optimum yang lebih tinggi, sedangkan untuk hubungan volume kepadatan, keduanya menunjukkan hasil yang hampir mendekati dan hubungan volume kecepatan maka pendekatan Greenshield dan Underwood masih lebih baik.

\section{Kesimpulan dan Saran}

\subsection{Kesimpulan}

Berdasarkan hasil penelitian dan pembahasan, maka dapat diambil beberapa kesimpulan sebagai berikut: Kecepatan lalu lintas paling rendah dan kepadatan lalu lintas tertinggi didapat pada hari senin yaitu $\mathrm{D}_{\mathrm{M}}$ sebesar 40,6231 smp/km dan

Komparasi Metode Greenshield, Greenberg Dan Underwood Terhadap Efektifitas Model Karakteristik Arus Lalu Lintas Pada Ruas Jalan Simpang 4 Bireuen - Adzuha Desmi, Lis Ayu Widari, Riza Yanti 
$\mathrm{S}_{\mathrm{M}}$ sebesar $0,19 \mathrm{~km} / \mathrm{jam}$, bentuk hubungan matematis antara kecepatan dan kepadatan lalu lintas menggunakan model Greenshield, Greenberg, Underwood menunjukkan kecepatan dengan kepadatan lalu lintas yang lemah, dan efektifitas model karakteristik arus lalu lintas adalah model yang paling optimum terdapat pada model Greenberg dikarenakan memiliki nilai yang lebih tinggi.

\subsection{Saran}

Perlu penelitian lebih lanjut untuk mendapatkan nilai yang lebih real dari ketiga model tersebut yaitu, Greenshield, Greenberg, dan Underwood, perbandingan perhitungan dengan menggunakan Manual Kapasitas Indonesia (MKJI 1997) pemodelan linear Greenshield, Greenberg dan Underwood perlu diteliti lagi dengan kondisi lalu lintas yang padat dan hambatan samping yang tinggi. Volume lalu lintas yang setiap tahunnya terus bertambah menjadi permasalahan terbesar bagi persimpangan.

\section{Daftar Kepustakaan}

Ahmad Munawar, 2005, Dasar-dasar Teknik Transportasi, Beta Offset,Yogyakarta.

Direktorat Jenderal Bina Marga, 1997, Manual Kapasitas Jalan Indonesia (MKJI 1997). Jakarta

Hendra Wibisana, 2007, Studi Hubungan Arus Lalu Lintas Di Ruas Jalan Rungkut Asri Kotamadya Surabaya Dengan Metode Underwood, Jurnal Teknik Sipil, Vol 3, No.2 Oktober 2007, Maranatha, Bandung.

Khisty C.J., Kent Lall., 2003,Transportation Engineering An Introduction, Third Edition, Prentice Hall, New Jersey.

Mcshare dan Roes, 1970, Model Persamaan Greenshield, Greenberg, dan Underwood. Universitas Gajah Mada Press, Yogjakarta.

Morlok, E.K, 1988, Pengantar Teknik dan perencanaan Transportasi. Terjemahan J.K Haini, Erlangga, Jakarta.

Ofyar Tamin, 2000, Hubungan Matematis Kecepatan Kepadatan Lalu Lintas, Universitas Gajah Mada Press, Yogjakarta.

Ririn Gamran, Freddy jansen,M.J.Paransa, 1977, Perbandingan Metode Greenshield, Greenberg, Underwood (MKJI 1997), Ratulangi.

Sudjana, 1992, Metode Stastistik, Transito, Bandung.

Tamin, O.Z, 2003, Perencanaan dan pemodelan Transportasi, ITB Bandung

Komparasi Metode Greenshield, Greenberg Dan Underwood Terhadap Efektifitas Model Karakteristik Arus Lalu Lintas Pada Ruas Jalan Simpang 4 Bireuen - Adzuha Desmi, Lis Ayu Widari, Riza Yanti 